\title{
Effects of the Lower Airway Secretions on Airway Opening Pressures and Suction Pressures in Critically III COVID-19 Patients: A Computational Simulation
}

\author{
Zhenglong Chen (i), ${ }^{1}$ Ming Zhong, ${ }^{2}$ Li Jiang, ${ }^{3}$ Nanshan Chen, ${ }^{4}$ Shengin Tu, ${ }^{4}$ Yuan Wei, ${ }^{4}$ Ling Sang, ${ }^{5}$ \\ Xia Zheng, ${ }^{6}$ Chunyuan Zhang, ${ }^{7}$ Jiale Tao, ${ }^{2}$ Linhong Deng, ${ }^{8}$ and Yuanlin Song ${ }^{9}$
}

${ }^{1}$ School of Medical Instrumentation, Shanghai University of Medicine \& Health Sciences, 257 Tianxiong Road, Shanghai 201318, China; ${ }^{2}$ Department of Intensive Care Medicine, Zhongshan Hospital, Fudan University, 180 Fenglin Road, Shanghai 200032, China; ${ }^{3}$ Department of Critical Care Medicine, Xuanwu Hospital, Capital Medical University, 45 Changchun Street, Xicheng District, Beijing 100053, China; ${ }^{4}$ Department of Respiratory and Critical Care Medicine, Wuhan Jinyintan Hospital, 1 Yintan Road, Dongxihu District, Wuhan 430023, China; ${ }^{5}$ Department of Critical Care Medicine, GuangZhou Institute of Respiratory Health, The First Affiliated Hospital of GuangZhou Medical University, 151 Yanjiangxi Road, Guangzhou 510120, China; ${ }^{6}$ Department of Critical Care Medicine, The First Affiliated Hospital of Zhejiang University, Hangzhou 310003, Zhejiang, China; ${ }^{7}$ NMPA Key Laboratory for Respiratory and Anaesthetic Equipment, 1 Jinyinhua Road, Shanghai 201321, China; ${ }^{8}$ Changzhou Key Laboratory of Respiratory Medical Engineering, Institute of Biomedical Engineering and Health Sciences, Changzhou University, Changzhou 213164, Jiangsu, China; and ${ }^{9}$ Department of Pulmonary Medicine, Zhongshan Hospital, Fudan University, 180 Fenglin Road, Xuhui District, Shanghai 200032, China

(Received 2 July 2020; accepted 3 October 2020; published online 19 October 2020)

Associate Editor Merryn Tawhai oversaw the review of this article.

\begin{abstract}
In patients with critically ill COVID-19 pneumonia, lower airways are filled with plenty of highly viscous exudates or mucus, leading to airway occlusion. The estimation of airway opening pressures and effective mucus clearance are therefore two issues that clinicians are most concerned about during mechanical ventilation. In this study we retrospectively analyzed respiratory data from 24 critically ill patients with COVID-19 who received invasive mechanical ventilation and recruitment maneuver at Jinyintan Hospital in Wuhan, China. Among 24 patients, the mean inspiratory plateau pressure was $52.4 \pm 4.4 \mathrm{cmH}_{2} \mathrm{O}$ (mean $\pm[\mathrm{SD}])$. Particularly, the capnograms presented an upward slope during the expiratory plateau, indicting the existence of airway obstruction. A computational model of airway opening was subsequently introduced to investigate possible fluid dynamic mechanisms for the extraordinarily high inspiratory plateau pressures among these patients. Our simulation results showed that the predicted airway opening pressures could be as high as $40-50 \mathrm{cmH}_{2} \mathrm{O}$ and the suction pressure could exceed $20 \mathrm{kPa}$ as the surface tension and viscosity of secretion simulants markedly increased, likely
\end{abstract}

Address correspondence to Ming Zhong, Department of Intensive Care Medicine, Zhongshan Hospital, Fudan University, 180 Fenglin Road, Shanghai 200032, China. Electronic mail: zhong_ming@fudan.edu.cn causing the closures of the distal airways. We concluded that, in some critically ill patients with COVID-19, limiting plateau pressure to $30 \mathrm{cmH}_{2} \mathrm{O}$ may not guarantee the opening of airways due to the presence of highly viscous lower airway secretions, not to mention spontaneous inspiratory efforts. Active airway humidification and effective expectorant drugs are therefore strongly recommended during airway management.

Keywords-Coronavirus disease 2019, Airway mucus, Airway opening pressure, Endotracheal suctioning, Respiratory mechanics.

\section{ABBREVIATIONS}

COVID-19 Coronavirus disease 2019

ECMO Extracorporeal membrane oxygenation

$\mathrm{ETCO}_{2} \quad$ End-tidal carbon dioxide

$\mathrm{FiO}_{2} \quad$ Fraction of inspiratory oxygen

FOB Fiberoptic bronchoscope

PEEP Positive end expiratory pressure

$\mathrm{PaCO}_{2} \quad$ Arterial partial pressure of carbon dioxide $\mathrm{PaO}_{2} \quad$ Arterial partial pressure of oxygen

PEO Polyethylene oxide

$\mathrm{P}_{\mathrm{ET}} \mathrm{CO}_{2} \quad$ End-tidal partial pressure of carbon dioxide 
SCMC Sodium carboxymethyl cellulose

$\mathrm{SpO}_{2} \quad$ Oxyhemoglobin saturation measured by pulse oximetry

\section{INTRODUCTION}

The coronavirus disease 2019 (COVID-19) is an infectious respiratory illness caused by severe acute respiratory syndrome coronavirus 2 (SARS-CoV2). 2,9,13,32 The World Health Organization (WHO) has declared COVID-19 pandemic a major public health emergency. As of July 2, 2020, a total of 216 countries and regions have reported more than 10.5 million confirmed cases of COVID-19 to WHO, and more than 512,000 people have lost their lives. ${ }^{25}$

Pathological findings from autopsy or lung biopsy showed that COVID-19 mainly involved injuries at the small airways and alveoli, manifested as: partial detachment of bronchial epithelium, gelatinous mucus attachment in the bronchial lumen, and large amount of sticky mucus and sputum plugs in small airways; jelly-like inflammatory exudates filling in the alveoli, significant proliferation of alveolar epithelial type II cells, desquamation of part pneumocytes, over-inflation of a small number of alveoli, rupture of alveolar septa and cysts formation..$^{20,29,31}$ These pathological changes were consistent with the main radiological features of patients with COVID 19, such as ground glass opacities, lung consolidation, air bronchograms and white lung appearance.

A particularly life-threatening problem for critically ill COVID-19 patients is the presence of excessive airway mucus and jelly-like alveolar exudates that lead to airway obstruction and decreased alveolar gas-exchange function. In such cases, the patients usually require mechanical ventilation at a high level of positive end expiratory pressure (PEEP), and a greater than $50 \%$ fraction of inspiratory oxygen $\left(\mathrm{FiO}_{2}\right)$ to help them breathe, as seen in a large portion of COVID-19 patients admitted to intensive care units (ICUs) in Lombardy, Italy. ${ }^{8}$

Therefore, how to clear sticky airway mucus and alveolar exudates (hereafter referred to as lower airway secretions) and maintain airway patency has become currently the most urgent issue in the ventilatory management of patients with severe COVID-19. In particular, the clinicians are most concerned with: (1) whether the opening of airways can be guaranteed with limitation of plateau pressure to $30 \mathrm{cmH}_{2} \mathrm{O}$; and (2) whether lower airway secretions can be suctioned out by a fiberoptic bronchoscope (FOB), and if possible, how much negative pressure is needed? Unfortunately, current technology limitations prevent in situ real-time observation and study of the dynamic events of opening in small airways and alveoli during mechanical ventilation. Instead, we used simulated lower airway secretions in a computational model to investigate the effects of changes in surface tension and rheological properties of lower airway mucus on the airway opening pressure and aspiration pressure in both healthy and diseased conditions similar to COVID-19. It is expected that results from this computational simulation could provide a theoretical reference for mechanical ventilation in severe COVID-19 patients, such as those admitted to the ICU at Jinyintan Hospital in Wuhan, China, as reviewed for respiratory data in this report.

\section{MATERIALS AND METHODS}

\section{Study Design and Participants}

A single-center, retrospective observational study was performed in a 30-bed ICU at Jinyintan Hospital in Wuhan, China. We retrospectively analyzed patients with laboratory-confirmed SARS-COV-2 infection from Feb 1, 2020, to Mar 15, 2020, who were critically ill, and received invasive mechanical ventilation and lung recruitment maneuver. The Ethics Committee of Jinyintan Hospital approved the study (KY-202056.01). Written informed consent was waived due to the retrospective manner of this study.

\section{Interventions}

All intubated patients were managed with the lung protective ventilation strategy, setting driving pressure between 15 and $18 \mathrm{cmH}_{2} \mathrm{O}$, and titrating optimal PEEP according to maximal lung compliance. ${ }^{1,16}$ Once $\mathrm{PaO}_{2} / \mathrm{FiO}_{2}$ ratio was lower than $150 \mathrm{mmHg}$, a lung recruitment maneuver was performed except in patients with unstable hemodynamics or pneumothorax or mediastinal emphysema. To establish a stable hemodynamics, we titrated $\mathrm{FiO}_{2}$ to maintain an oxygen saturation $\left(\mathrm{SpO}_{2}\right)$ of $88 \%$. If $\mathrm{SpO}_{2}$ could not achieve a target value of $88 \%$ or above at a $100 \% \mathrm{FiO}_{2}$, a lung recruitment maneuver was initiated with $\mathrm{FiO}_{2}$ set at $100 \%$. During lung recruitment, mechanical ventilation mode was pressure control ventilation at a driving pressure of $15 \mathrm{cmH}_{2} \mathrm{O}$ and PEEP of $30-45 \mathrm{cmH}_{2} \mathrm{O}$ depending on the patient's response. PEEP was initially set at $30 \mathrm{cmH}_{2} \mathrm{O}$ for $1 \mathrm{~min}$, then returned to 15 $\mathrm{cmH}_{2} \mathrm{O}$ for a 4-min observational period to check whether there was a response to recruitment maneuver. If no response occurred, we repeated the above 
recruitment maneuver with an increased PEEP in 5 $\mathrm{cmH}_{2} \mathrm{O}$ steps until a response emerged. A response to recruitment maneuver was defined as $\mathrm{SpO}_{2}$ no less than $96 \%$ or a more than $8 \%$ increase in $\mathrm{SpO}_{2}$. And if the maximum PEEP of $45 \mathrm{cmH}_{2} \mathrm{O}$ was reached and still there was no response present, recruitment maneuver was terminated to avoid barotrauma and the patient was deemed as a non-responder.

\section{Data Collection}

Respiratory system mechanics, end-tidal partial pressure of carbon dioxide $\left(\mathrm{P}_{\mathrm{ET}} \mathrm{CO}_{2}\right)$, blood gas analysis, and hemodynamic parameters were recorded for each patient immediately before and after lung recruitment maneuver. Subsequent to the lung recruitment maneuver, the patient was examined on chest radiography to rule out possible barotrauma.

\section{Theory and Model of Airway Reopening}

Closure of the distal airways at low lung volumes can occur through two mechanisms, namely, "liquid bridge formation" and "compliant collapse". In the former case, the unstable lining fluid leads to a fluid plug formation spanning the lumen of an undeformed airway. In the latter case, the deformed airway wall bends inward and the lining fluid adheres to the wall. In general, airway closure occurs in terminal bronchioles with the diameters of airways to be as small as $0.25 \mathrm{~mm}$ and as large as $2-4 \mathrm{~mm}$. $7,14,33$

Among several models to describe the fluid dynamics of airway reopening, the most relevant to the clinical observations of the airway opening process is the one developed by Gaver et al. as shown in Fig. 1. 4,6,24 In this model, the peripheral airway collapses in a ribbon-like configuration. The open region of a cylindrical airway has radius $\mathrm{R}$, and the lining fluid in the closed portion has thickness $\mathrm{H}$.
To reopen this collapsed airway a finger of air must progress through the structure and separate the walls in a peeling motion. From the viewpoint of fluid mechanics, the total pressure $\left(P_{\text {total }}^{*}\right)$ required to displace the viscous lining fluid by the air-liquid meniscus interface mainly includes two components: the capillary pressure and the viscous pressure. Gaver and coworkers further showed that the total pressure can be expressed as

$$
P_{\text {total }}^{*} R / \gamma=P_{\text {cap }}+\left\{\frac{\mu U}{\gamma}\right\} P_{\text {vis }}=P_{\text {cap }}+\mathrm{Ca} \cdot P_{\text {vis }}
$$

where $\gamma$ and $\mu$ are the surface tension and viscosity of the lining fluid, $U$ represents the velocity of the air finger, and $P_{\text {cap }}$ and $P_{\text {vis }}$ are the dimensionless capillary and viscous pressures. The dimensionless quantity $\mu U / \gamma$ is defined as the capillary number (or dimensionless velocity), $\mathrm{Ca}$, that represents the relative importance of viscous to surface tension effects on airway reopening. The Eq. (1) clearly shows that: (1) the smaller the airway radius is, the higher $P_{\text {total }}^{*}$; (2) the faster the airway reopening is, the higher $P_{\text {total }}^{*}$ needed; and (3) $P_{\text {total }}^{*}$ increases with increasing the surface tension or fluid viscosity.

Utilizing in-vitro models of the pulmonary airway reopening, the effects of surface tension and flow properties (viscosity, viscoelasticity, and yield stress) of both Newtonian and non-Newtonian fluids on the airway reopening have been investigated. ${ }^{6,12,21}$ A typical study by Low at al. tested simulated lining fluids with surface tensions and rheological properties in the range as reported for both healthy and diseased human sputum, and a set of regression equations were obtained that show how the characteristics of the lining fluid and the airway radius influence the opening pressure-velocity relationship (see Table 1). ${ }^{21}$ These equations were used to roughly estimate the airway

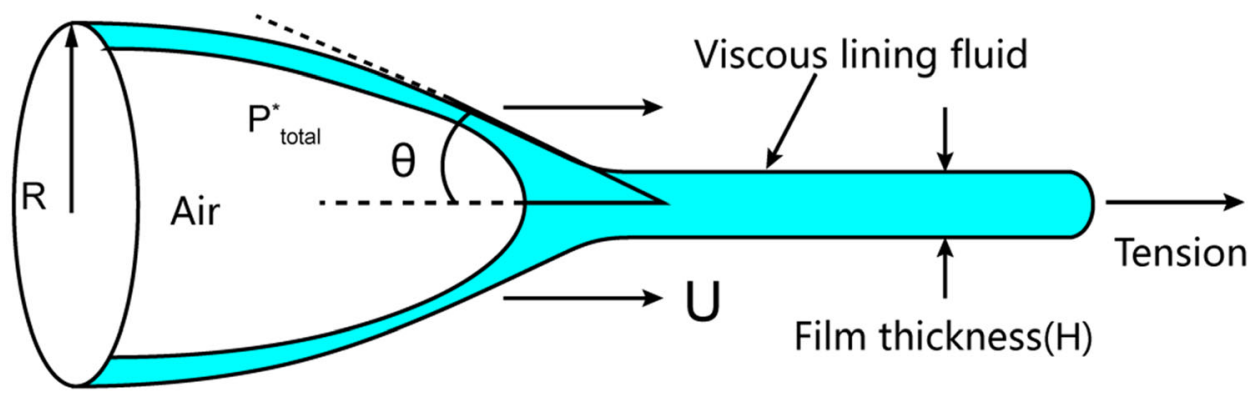

FIGURE 1. Airway reopening model. $R$ is the radius of the flexible-walled tube. $H$ is the thickness of upstream film, and $T$ is imposed axial wall tension. Positive pressure $\boldsymbol{P}_{\text {total }}^{*}$ is applied to gas phase, peeling apart the tube at velocity $U$ and opening angle $\theta$. 
TABLE 1. The dimensionless airway reopening pressure-velocity relationship with various lining fluids. ${ }^{21}$

\begin{tabular}{lcc}
\hline Lining fluid & The dimensionless pressure-velocity relationship & Capillary number \\
\hline Newtonian fluids & $\mathrm{PR} / \gamma=4.39+21.96 \mathrm{Ca}{ }^{0.5} \quad \mathrm{Ca} \leq 0.75(2 \mathrm{a}) \mathrm{PR} / \gamma=21.29+$ & $\mathrm{Ca} \equiv \mu U / \gamma$ \\
Shear-Thinning Fluids & $4.81 \mathrm{Ca} \quad 0.75 \leq \mathrm{Ca} \leq 86.56(2 \mathrm{~b})$ & $\mathrm{Ca} \equiv \frac{m}{\gamma} \frac{U^{n}}{(0.5 H)^{n-1}}$ \\
Yield stress fluids & $\mathrm{PR} / \gamma=3.42+19.06 \mathrm{Ca} \mathrm{s} \quad 0.02 \leq \mathrm{Ca}_{\mathrm{s}} \leq 2.0(3)$ & $\mathrm{Ca} \equiv \frac{m}{\tau_{\mathrm{y}}} \frac{\mathrm{U}^{n}}{(0.5 H)^{n}}$ \\
\hline
\end{tabular}

$\mathrm{Ca}$ dimensionless velocity for Newtonian Fluids, represents the relative magnitudes of the viscous and capillary pressures, $C a_{S}$ dimensionless velocity for shear thinning fluids, $C a_{y}$ dimensionless velocity for yield stress fluids ${ }^{21}, H$ lining fluid film thickness, $m$ consistency parameter, $n$ power-law index, $P$ air finger pressure, $R$ tube radius, $\gamma$, surface tension of lining fluid, $\tau_{y}$, yield stress of lining fluid.

TABLE 2. Properties of the simulated lower airway secretions.

\begin{tabular}{|c|c|c|c|c|}
\hline Types of secretion simulants & $\begin{array}{c}\text { Surface } \\
\text { tension } \\
(\mathrm{dyn} / \mathrm{cm})\end{array}$ & $\begin{array}{l}\text { Consistency } \\
\text { parameter } \\
\left(\mathrm{dyn} / \mathrm{cm}^{2}\right) \mathrm{s}^{\mathrm{n}}\end{array}$ & $\begin{array}{c}\text { Yield } \\
\text { stress } \\
\left(\mathrm{dyn} / \mathrm{cm}^{2}\right)\end{array}$ & $\begin{array}{c}\text { Power-law } \\
\text { index }(n)\end{array}$ \\
\hline \multicolumn{5}{|l|}{ Newtonian fluids } \\
\hline Simulated fluid (1) & 25 or 50 & 0.01 & 0 & 1 \\
\hline Simulated fluid (2) & 25 or 50 & 0.1 & 0 & 1 \\
\hline Simulated fluid (3) & 20 or 50 & 1 & 0 & 1 \\
\hline Simulated fluid (4) & 20 or 50 & 10 & 0 & 1 \\
\hline \multicolumn{5}{|l|}{ Non-Newtonian fluids ${ }^{a}$} \\
\hline SCMC $1 \%$ & 70.6 & 24.9 & 0 & 0.560 \\
\hline PEO 3.2\% & 66.7 & 41.9 & 0 & 0.567 \\
\hline SCMC $2 \%$ & 68.0 & 255.1 & 0 & 0.375 \\
\hline Ghee & $-{ }^{\mathrm{b}}$ & 3.7 & 164 & 0.840 \\
\hline Grease & - & 98.1 & 235 & 0.618 \\
\hline Peanut Butter & - & 130.8 & 400 & 0.705 \\
\hline Mayonnaise & - & 104.1 & 600 & 0.471 \\
\hline
\end{tabular}

All the fluid properties were measured at a temperature of $29^{\circ} \mathrm{C}$.

${ }^{a}$ The rheological parameters of non-Newtonian fluids obtained from Ref. 21 , ${ }^{\mathrm{b}}$ For yield pseudoplastic fluids the surface tension was assumed relatively insignificant.

reopening pressures in both healthy and diseased conditions in the next section.

\section{Model Parameters}

As described above, airway closure might take place at the levels of small bronchi to terminal bronchioles. Thus, we will accordingly calculate the pressures to open 8-14 generation airways according to a Weibel lung geometry. Considering the typical ventilator settings, for example, tidal volume $400 \mathrm{~mL}$ and inspiratory time $1 \mathrm{~s}$, and assuming all generations of airways to be in the critical opening state, the average opening velocity $U_{\mathrm{n}}(n=8-14)$ in each generation could be roughly estimated by the total cross-sectional area of the each airway generation.

Various types of simulated lower airway secretions are listed in Table 2, including both Newtonian and non-Newtonian fluids. The properties of these simulated lower airway secretions are comparable with those of healthy and diseased respiratory secretions. ${ }^{3,18}$ One type of secretion simulants, such as sodium car- boxymethyl cellulose (SCMC) and polyethylene oxide (PEO) ${ }^{21}$ behaved like a pseudoplastic fluid and was therefore described by the power-law relationship, $\tau=m \dot{\gamma}^{n}$, where $\tau$ and $m$ are the shear stress and the consistency of fluid, $\dot{\gamma}$ is the shear rate, and $\mathrm{n}$ is a measure of the degree of shear-thinning; the other type of secretion simulants, for example ghee, grease, peanut butter and mayonnaise, showed the behavior of a yield pseudoplastic fluid and was described by the Hershcel-Buckley model, $\tau-\tau_{\mathrm{y}}=m \dot{\gamma}^{n}$, where $\tau_{\mathrm{y}}$ is the yield stress.

\section{RESULTS}

\section{Demographics and Characteristics}

A total of 24 patients with COVID-19 were included in this retrospective study (Table 3 ). The average age was $59.5 \pm 11.8$ years, and $16(66.7 \%)$ were male. Among those patients responded to lung recruitment maneuver, the minimal and maximal inspiratory plateau pressures were $45 \mathrm{cmH}_{2} \mathrm{O}$ and $60 \mathrm{cmH}_{2} \mathrm{O}$, 
TABLE 3. Demographic and clinical characteristics.

\begin{tabular}{|c|c|c|c|c|c|c|c|c|}
\hline $\begin{array}{l}\text { Patient } \\
\text { No. }\end{array}$ & $\begin{array}{l}\text { Age } \\
\text { (year) }\end{array}$ & $\begin{array}{l}\text { Sex } \\
(\mathrm{M} / \mathrm{F})\end{array}$ & $\begin{array}{l}\mathrm{P}_{\mathrm{ET}} \mathrm{CO}_{2} \\
(\mathrm{mmHg})\end{array}$ & $\begin{array}{l}\mathrm{PaCO}_{2} \\
(\mathrm{mmHg})\end{array}$ & $\begin{array}{c}\mathrm{PaO}_{2} / \mathrm{FiO}_{2} \\
(\mathrm{mmHg})\end{array}$ & $\begin{array}{c}\text { Cstat } \\
\left(\mathrm{mL} / \mathrm{cmH}_{2} \mathrm{O}\right)\end{array}$ & $\begin{array}{c}\text { PEEP } \\
\left(\mathrm{cmH}_{2} \mathrm{O}\right)\end{array}$ & $\begin{array}{c}F V_{D} \\
\left(\% \text { of } V_{T}\right)\end{array}$ \\
\hline 1 & 58 & $\mathrm{~F}$ & 69 & 115 & 86 & 13 & 35 & 0.40 \\
\hline 2 & 29 & $M$ & 36 & 71 & 146 & 28 & 30 & 0.49 \\
\hline 3 & 52 & $M$ & 43 & 79 & 76 & 18 & 45 & 0.46 \\
\hline 4 & 71 & $\mathrm{~F}$ & 48 & 86 & 82 & 26 & 35 & 0.44 \\
\hline 5 & 64 & $M$ & 37 & 75 & 132 & 32 & 35 & 0.51 \\
\hline 6 & 65 & $M$ & 28 & 59 & 94 & 37 & 35 & 0.53 \\
\hline 7 & 65 & $\mathrm{~F}$ & 26 & 57 & 135 & 25 & 40 & 0.54 \\
\hline 8 & 50 & $\mathrm{~F}$ & 36 & 63 & 101 & 11 & 45 & 0.43 \\
\hline 9 & 57 & $M$ & 48 & 88 & 114 & 31 & 40 & 0.45 \\
\hline 10 & 64 & $M$ & 50 & 73 & 123 & 19 & 35 & 0.32 \\
\hline 11 & 50 & $\mathrm{~F}$ & 34 & 52 & 156 & 37 & 30 & 0.35 \\
\hline 12 & 63 & $M$ & 37 & 61 & 148 & 18 & 35 & 0.39 \\
\hline 13 & 64 & $M$ & 58 & 93 & 86 & 28 & 40 & 0.38 \\
\hline 14 & 53 & $M$ & 35 & 83 & 126 & 20 & 35 & 0.58 \\
\hline 15 & 91 & $M$ & 37 & 68 & 63 & 12 & 45 & 0.46 \\
\hline 16 & 77 & $M$ & 29 & 63 & 94 & 21 & 40 & 0.54 \\
\hline 17 & 69 & $M$ & 49 & 72 & 110 & 26 & 35 & 0.32 \\
\hline 18 & 51 & $\mathrm{~F}$ & 36 & 67 & 65 & 22 & 40 & 0.46 \\
\hline 19 & 52 & $M$ & 38 & 76 & 90 & 29 & 35 & 0.50 \\
\hline 20 & 61 & $M$ & 62 & 91 & 62 & 19 & NA & 0.32 \\
\hline 21 & 47 & $M$ & 25 & 59 & 52 & 15 & NA & 0.58 \\
\hline 22 & 55 & $\mathrm{~F}$ & 36 & 77 & 59 & 27 & 35 & 0.53 \\
\hline 23 & 59 & $M$ & 34 & 72 & 61 & 22 & NA & 0.53 \\
\hline 24 & 61 & $\mathrm{~F}$ & 57 & 81 & 54 & 18 & 40 & 0.30 \\
\hline Mean \pm SD & $59.5 \pm 11.8$ & $16 \mathrm{M} / 8 \mathrm{~F}$ & $41.2 \pm 11.6$ & $74.2 \pm 14.1$ & $96.5 \pm 32.4$ & $23.1 \pm 7.3$ & $37.4 \pm 4.4$ & $0.45 \pm 0.09$ \\
\hline
\end{tabular}

$P_{E T} C_{2}$ end-tidal partial pressure of carbon dioxide, $\mathrm{PaCO}_{2}$ arterial partial pressure of carbon dioxide, $\mathrm{PaO}$ arterial partial pressure of oxygen, $\mathrm{FiO}_{2}$ inspired oxygen fraction, Cstat static compliance of the respiratory system, $P E E P$ positive end-expiratory pressure, $F V_{D}$ alveolar dead space fraction (percent of tidal volume), which is calculated as the ratio of the difference between $\mathrm{PaCO}_{2}$ and $\mathrm{P}_{\mathrm{ET}} \mathrm{CO}_{2}$ to $\mathrm{PaCO}_{2}, V_{T}$ tidal volume, $N A$ not available.

respectively, and the mean was $52.4 \pm 4.4 \mathrm{cmH}_{2} \mathrm{O}$ (the mean value of PEEP plus a driving pressure of 15 $\mathrm{cmH}_{2} \mathrm{O}$ ). Of note, the alveolar-dead space was calculated as the difference between $\mathrm{PaCO}_{2}$ and $\mathrm{P}_{\mathrm{ET}} \mathrm{CO}_{2}$ divided by $\mathrm{PaCO}_{2}$, the average of which was $45 \%$ of tidal volume among patients studied.

Figure 2 shows capnograms derived from six critically ill patients with COVID-19. Patients a and c had a relatively normal capnogram shape, the elevation angle of the alveolar plateau was about 31 and $19.5^{\circ}$ respectively; whereas in patients $b, d$, e and $f$, the $\mathrm{CO}_{2}$ waveform presented a "shark's fin" 27 or spike-like appearance, the elevation angle of the alveolar plateau was approximately $48.5,66,59.5$, and $72^{\circ}$, respectively. The peak end-tidal carbon dioxide $\left(\mathrm{ETCO}_{2}\right)$ was 28 and $26 \mathrm{mmHg}$ in patients $\mathrm{b}$ and c respectively, slightly lower than normal levels of $35-45 \mathrm{mmHg}$; whereas the peak was $69 \mathrm{mmHg}$ in patient $\mathrm{d}$, obviously higher than normal values.

\section{Airway Reopening Pressures}

In a normal lung with the equilibrium surface tension $\gamma=25 \mathrm{dyn} / \mathrm{cm}$ and the viscosity of airway mucus similar to that of water ( $\mu=0.01$ Poise), the airway reopening pressures of generations 8-14 ranged from 2.1 to $3.8 \mathrm{cmH}_{2} \mathrm{O}$ (star in Fig. 3), relatively smaller than the minimal PEEP of $5 \mathrm{cmH}_{2} \mathrm{O}$ recommended by the ARDSnet protective ventilatory strategy. However, as the surface tension or viscositiy of the simulated airway secretions increased, the airway reopening pressure increased correspondingly. In particular, if in diseased lung the viscosity of secretions rose to 10 poise (similar to that of medicinal glycerin), the airway reopening pressure of generation 8 may increase to about $36 \mathrm{cmH}_{2} \mathrm{O}$, appreciably exceeding the plateau pressure limitation of $30 \mathrm{cmH}_{2} \mathrm{O}$; if the surface tension simultaneously increased to $50 \mathrm{dyn} / \mathrm{cm}$, the airway reopening pressures of generations 8-14 may be all greater than $35 \mathrm{cmH}_{2} \mathrm{O}$ (inverted triangles in Fig. 4), with the maximum reopening pressure of $41.8 \mathrm{cmH}_{2} \mathrm{O}$ occurring at generation 8 .

It is interesting to note that although the values of surface tension and consistency of SCMC $2 \%$ were all greater than those of simulated fluid (4) (surface tension 68 vs. $50 \mathrm{dyn} / \mathrm{cm}$; consistency 255.1 vs. $10 \mathrm{dyn} /$ $\mathrm{cm}^{2} \mathrm{~s}^{n}$, see Table 2), the airway reopening pressures of generations $8-14$ lining with SCMC 2\% were all less 


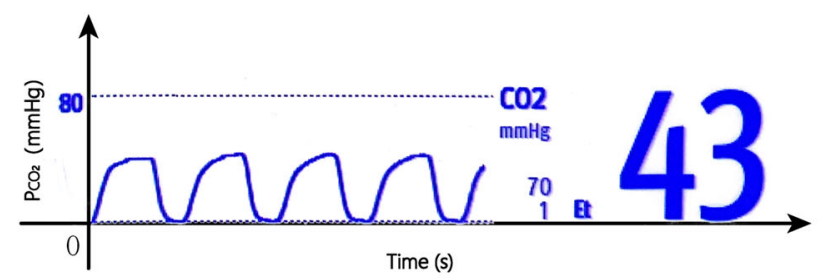

(a)

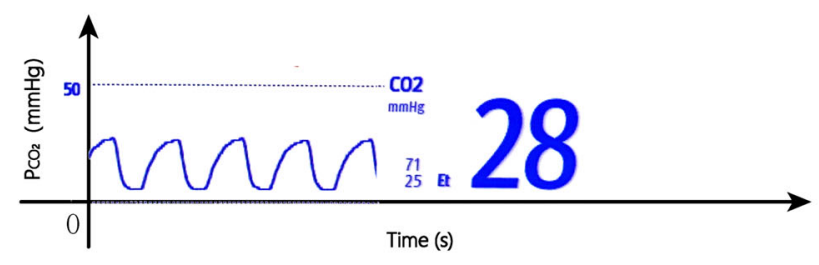

(b)

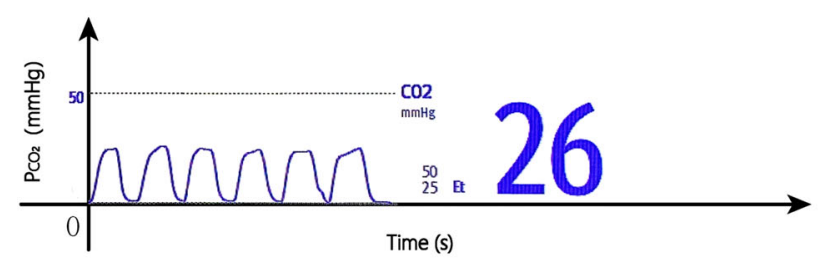

(c)

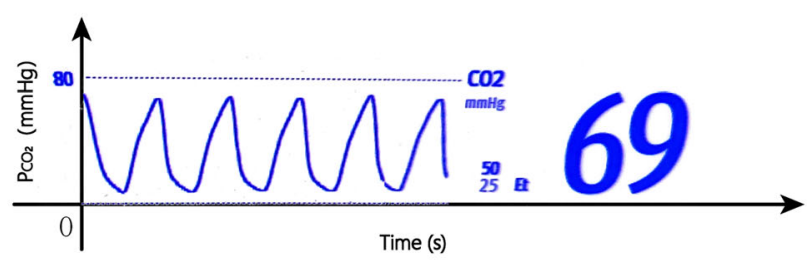

(d)

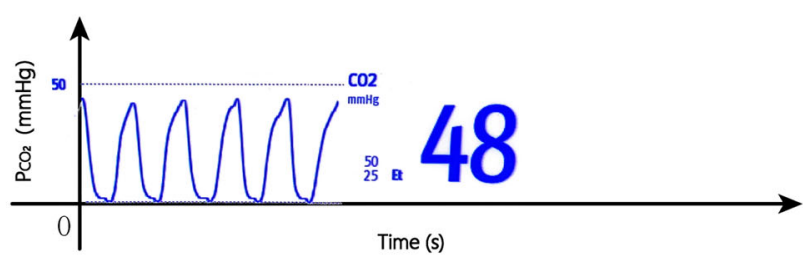

(e)

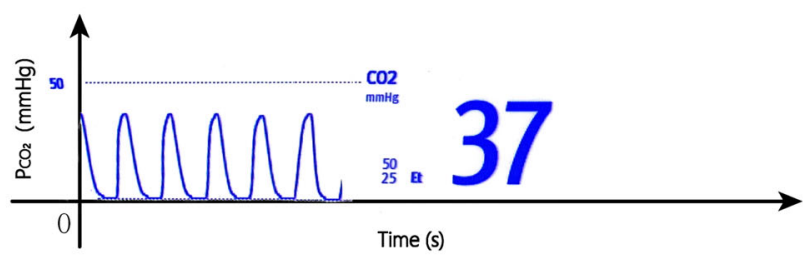

(f)

FIGURE 2. Graphic recording of end-tidal $\mathrm{CO}_{2}$ curves in six critically ill patients with COVID-19.

than $13 \mathrm{cmH}_{2} \mathrm{O}$ in all cases (Fig. 5), apparently lower than those of generations $8-14$ lining with simulated fluid (4) ( $>35 \mathrm{cmH}_{2} \mathrm{O}$, inverted triangles in Fig. 4). This finding indicated that shear thinning effect may reduce the airway reopening pressure. In addition, Fig. 5 also shows that the airway reopening pressure increased with an increase in the thickness of lining fluid.

When the airways were filled with yield stress fluids such as ghee (low consistency) or mayonnaise (small power-law index), the corresponding airway reopening pressures were smaller than $6.5 \mathrm{cmH}_{2} \mathrm{O}$ (star and inverted triangle in Fig. 6). But when they were filled with fluids like peanut butter $\left(m=130.8 \mathrm{dyn} / \mathrm{cm}^{2} \mathrm{~s}^{n}, \tau_{\mathrm{y}}=400 \mathrm{dyn} / \mathrm{cm}^{2}, \quad\right.$ and $\mathrm{n}=0.705)$, the airway reopening pressures may be as high as $30.1 \mathrm{cmH}_{2} \mathrm{O}$ or even $48.9 \mathrm{cmH}_{2} \mathrm{O}$ (triangle Fig. 6), depending on the thickness of fluid.

\section{Suction Pressures}

The FOB used for the removal of airway secretions generally has an effective length of $550-600 \mathrm{~mm}$ and a
3.5-5 $\mathrm{mm}$ tip diameter. It can be inserted down to segmental or small bronchi (generations 4-5) at most. In each endotracheal suctioning procedure, the suctioning time is generally not more than $15 \mathrm{~s}$, and negative pressure applied is usually $7-10 \mathrm{kPa}$, allowing a maximal pressure of $13 \mathrm{kPa} .{ }^{19}$ When performing suction of airway secretions, the patient are normally in the supine position, and therefore the gravity has an insignificant effect on the movement of secretions along the catheter. Unless 5 to 4 generations of airways are completely occluded by secretions, there is always an air-liquid interface between the tip of FOB and secretions. Therefore, the suction pressure must overcome the capillary force generated by the surface tension of the air-liquid interface and the viscous friction in the fluid.

Theoretical and experimental studies by Gaver and Yap showed that an apparent "yield pressure" must be exceeded before airway occlusion fluids started to flow. ${ }^{6,33}$ This yield pressure is determined by the equation $P_{\text {yield }}=\gamma k=K \gamma / R$, where $\mathrm{K}$ is the geometric parameter that relates the airway radius $(\mathrm{R})$ to the radius of curvature of the meniscal air-liquid, 1/k. As 


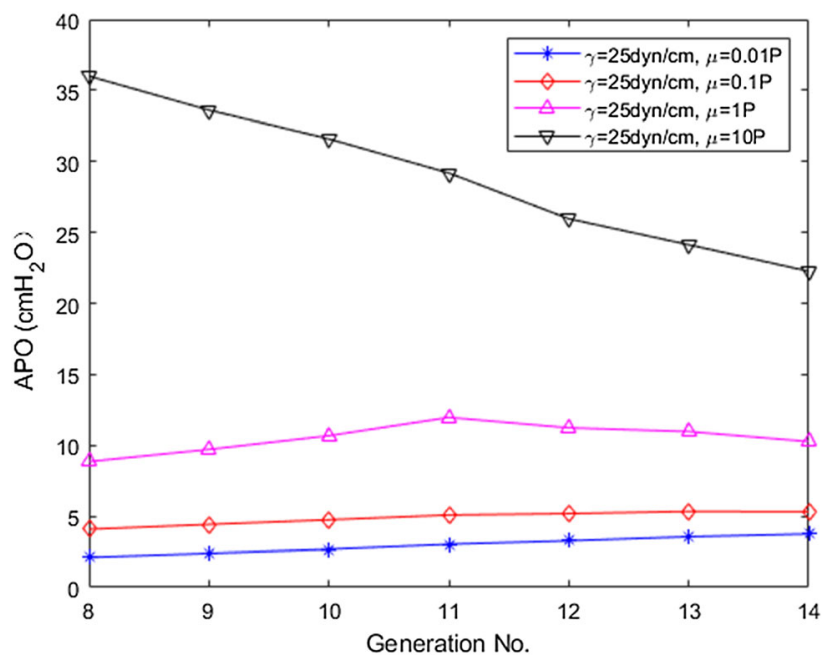

FIGURE 3. Effects of surface tension and viscosity of Newtonian lining liquids on airway reopening pressures. It is assumed that in a normal lung the equilibrium surface tension and viscosity of airway lining fluid are $25 \mathrm{dyn} / \mathrm{cm}$ and 0.01 poise, respectively. In a diseased lung, the values of viscosity are assumed to increase to $0.1,1$ or 10 poise. Note that the airway reopening pressures of generations 8-14 are less than $5 \mathrm{cmH}_{2} \mathrm{O}$ in a normal lung and that the airway reopening pressure of generation 8 may rise to as high as $36 \mathrm{cmH}_{2} \mathrm{O}$ if the value of viscosity increases to 10 poise in a diseased lung. 1 poise $=0.1 \mathrm{Pas}=1 \mathrm{dyn} / \mathrm{cm}^{2} \mathrm{~s} ; 1 \mathrm{dyn}=10^{-5} \mathrm{~N}$.

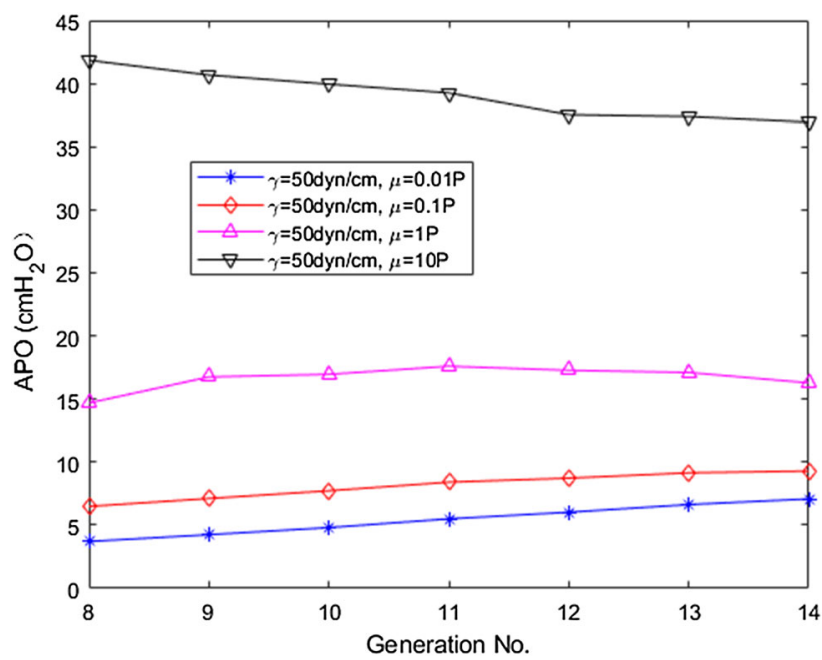

FIGURE 4. Effects of surface tension and viscosity of Newtonian lining liquids on airway reopening pressures. It is assumed that in a diseased lung the equilibrium surface tension airway lining fluid increases to $50 \mathrm{dyn} / \mathrm{cm}$ and that the viscosity increase from a normal value of 0.01 poise to $0.1,1$ or 10 poise respectively. Note that as compared with Fig. 3 , an increased surface tension leads to an increasing in the airway reopening pressures. As the surface tension and viscosity elevates to $50 \mathrm{dyn} / \mathrm{cm}$ and 10 poise respectively, the airway reopening pressure of generation 8 may reach $41.8 \mathrm{cmH}_{2} \mathrm{O}$. 1 poise $=0.1 \mathrm{Pas}=1 \mathrm{dyn} / \mathrm{cm}^{2} \mathrm{~s} ; 1 \mathrm{dyn}=10^{-5} \mathrm{~N}$.

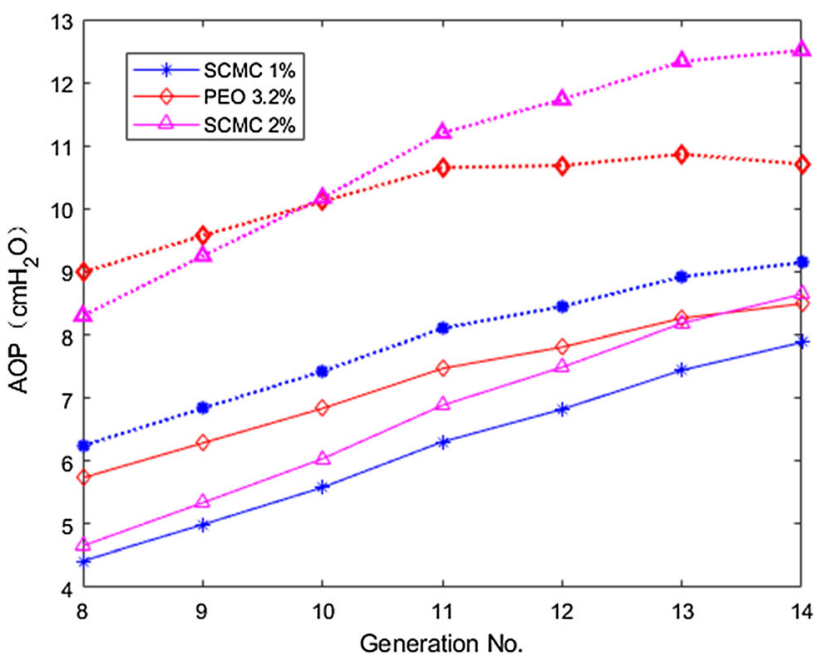

FIGURE 5. The airway reopening pressures of generations 8-14 for non-Newtonian lining liquids (pseudoplastic fluids). Solid line and dash line show the thickness of lining liquids $H=10$ and $50 \mu \mathrm{m}$. Of note, although the values of surface tension and consistency of three pseudoplastic fluids were all greater than those of simulated fluid (4) (Table 2), the airway reopening pressures are less than $13 \mathrm{cmH}_{2} \mathrm{O}$, which are appreciably lower than those for simulated fluid (4) (> 35 $\mathrm{cmH}_{2} \mathrm{O}$, inverted triangles in Fig. 4), indicating that shear thinning effect may reduce the airway reopening pressure.

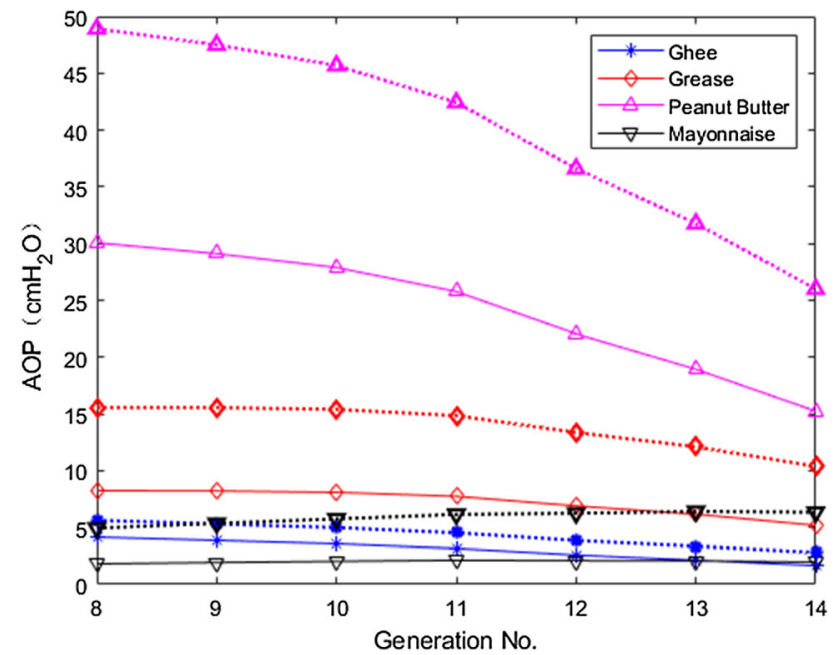

FIGURE 6. The airway reopening pressures of generations 8-14 for non-Newtonian lining liquids (yield pseudoplastic fluids). Solid line and dash line show the thickness of lining liquids $H=10$ and $50 \mu \mathrm{m}$. Note that the airway reopening pressures may be as high as $48.9 \mathrm{cmH}_{2} \mathrm{O}$ when the airway is filled with peanut butter-like liquid $\left(m=130.8 \mathrm{dyn} / \mathrm{cm}^{2} \mathrm{~s}^{\mathrm{n}}, \tau_{\mathrm{y}}=400 \mathrm{dyn} / \mathrm{cm}^{2}\right.$, and $\mathrm{n}=0.705$, Table 2). Although mayonnaise has the highest yield stress $\left(\tau_{y}=600 \mathrm{dyn} / \mathrm{cm}^{2}\right.$, Table 2), the corresponding airway reopening pressures are lower than $6.5 \mathrm{cmH}_{2} \mathrm{O}$ due to its strong shear thinning effect $(n=0.471$, Table 2$)$. 
such, we made a rough estimation of yield pressures for airway generations 8 to 14 in the case of secretions to be Newtonian fluids (Table 2). These results are shown in Fig. 7. Of note, cartilage disappears anatomically from the airway wall beyond the eleventh generation and air passages are directly embedded in the lung parenchyma. Yap et $a{ }^{33}$ found that the critical transmural pressure $\left(P_{\text {trans }}\right)$ required to prevent compliant collapse of noncartilaginous 2- to $3-\mathrm{mm}$ airways was approximately $7.5 \mathrm{cmH}_{2} \mathrm{O}$. However, it can be seen from Fig. 7 that when the surface tension increased to $\gamma=50 \mathrm{dyn} / \mathrm{cm}$ in diseased conditions, yield pressure needed to begin occlusion fluids motion is already higher than the critical transmural pressure of $7.5 \mathrm{cmH}_{2} \mathrm{O}$. This means that before occlusion fluids flow, compliant collapse of the airway has very likely taken place, which hence impedes an effective removal of lower airway secretions.

Next, we calculate the pressure drop when the secretions pass through the suction catheter in the FOB. Let the working length $(L)$ and the inner diameter of the suction catheter $(d)$ be $60 \mathrm{~cm}$ and $2 \mathrm{~mm}$, respectively. If the duration of suctioning is $15 \mathrm{~s}$, then the movement speed of secretions $(U)$ must be greater than $4 \mathrm{~cm} / \mathrm{s}$. As a

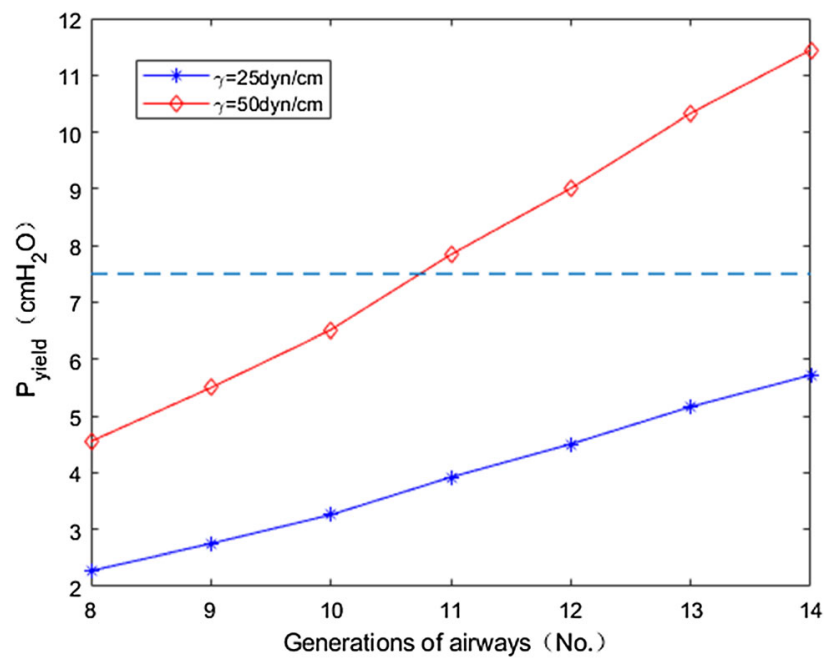

FIGURE 7. The yield pressures of 8 to 14 generations of airways with surface tension of occlusion fluids $\gamma=25$ or $50 \mathrm{dyn} / \mathrm{cm}$. The dash line indicates the critical transmural pressure $P_{\text {trans }}=7.5 \mathrm{cmH}_{2} \mathrm{O}$ needed to prevent compliant collapse of airways. relatively conservative estimation, we consider the volume of secretions aspirated into the FOB just to be $0.2 \mathrm{~mL}$, which corresponds an approximately $6.4 \mathrm{~cm}$ long secretions column. Then, the loss of pressure head $\Delta P$ can be calculated by Poiseuille's Law

$$
\Delta P=32 \mu L U / d^{2}
$$

where $\mu$ is the viscosity of secretions. Substituting the corresponding values into Eq. (5), we obtained the relationship between the loss of pressure head and the viscosity of secretions shown in Table 4 .

\section{DISCUSSION}

Based on the computational and experimental models of pulmonary airway opening, this study examined the effects of physical properties of lower airway secretions on airway reopening pressures and suction pressures. Our results showed that the airway reopening pressure was dependent on surface tension of the air-liquid interface, consistency and yield stress of secretions, the volume of secretions, airway radius as well as airway opening velocity. In a healthy lung with $\gamma=25 \mathrm{dyn} / \mathrm{cm}$ and $\mu=0.01$ poise, the predicted airway reopening pressures for generations 8-14 range between 2.1 and $3.8 \mathrm{cmH}_{2} \mathrm{O}$; however, if in diseases like COVID-19 the viscosity of lower airway secretions increased by three orders of magnitude to 10 poise, similar to that of medicinal glycerin, the predicted airway reopening pressure may reach as high as $35-42$ $\mathrm{cmH}_{2} \mathrm{O}$, even 30-49 $\mathrm{cmH}_{2} \mathrm{O}$ if lower airway secretions become like peanut butter. Accordingly, the loss of pressure head during endotracheal suctioning may exceed $20 \mathrm{kPa}$, making it almost impossible to remove sticky secretions. For some critically ill patients with COVID-19, limiting plateau pressure to $30 \mathrm{cmH}_{2} \mathrm{O}$ under a lung-protective ventilation strategy might not guarantee a complete opening of the pulmonary airways and an improved oxygenation, leading to the failure of mechanical ventilation.

\section{Validity of the Computational Model}

We first discussed the possible ranges of surface tension and rheological parameters of lower airway

TABLE 4. Relationship between pressure loss and viscosity of secretions.

\begin{tabular}{llcc}
\hline Type of secretions & Viscosity (poise) & Movement speed (cm/s) & Pressure loss (kPa) \\
\hline Purified water at $20{ }^{\circ} \mathrm{C}$ & $\sim 0.01$ & 4 & 0.020 \\
Cocoa butter at $45{ }^{\circ} \mathrm{C}$ & $\sim 0.1$ & 4 & 0.204 \\
Cream $50 \%$ fat content at $16{ }^{\circ} \mathrm{C}$ & $\sim 1$ & 4 & 2.037 \\
Medicinal glycerin at $25{ }^{\circ} \mathrm{C}$ & $\sim 10$ & 4 & 20.37 \\
\hline
\end{tabular}


secretions in COVID-19 patients. Due to a lack of direct measurement of surface properties of alveolar exudates and airway mucus in patients with COVID19 , surface tension and rheology of the simulated lower airway secretions in this simulation study were referred to reported literature values of human mucus in patients with chronic bronchitis, bronchiectasis, pneumonia, cystic fibrosis and ARDS. But considering the fact that a portion of patients with relatively severe COVID-19 pneumonia progress to ARDS and that COVID-19 pneumonia is essentially a lung inflammation caused by viral infections, ${ }^{30}$ we therefore speculate that the composition of pulmonary secretions is basically similar across diseases mentioned above, mainly including mucins, plasma proteins, inflammatory cells, DNA, actin, bacteria, viruses and so on. ${ }^{15}$ As such, the real values of surface tension and rheological parameters should fall within the range discussed in this study.

Macklem et al. found the airway opening pressure for 0.5 -mm-diameter airways ranged from $5-9 \mathrm{cmH}_{2} \mathrm{O}$ when pulmonary surfactant were present. ${ }^{23}$ If we assume the equilibrium surface tension to be $\gamma=25 \mathrm{dyn} / \mathrm{cm}$, this opening pressure correspond to 5-9

$\gamma / R$, in good agreement with capillary pressure term $P_{\text {cap }}^{*} \approx 4.39 \gamma / R$ in equation (2a). Using this regression relationship, we can further obtain the opening pressure to be about $5.6 \mathrm{cmH}_{2} \mathrm{O}$ for airways $0.5 \mathrm{~mm}$ in diameter. Crotti et al. studied threshold opening pressures (TOPs) for lung recruitment in five ALI/ ARDS patients and found that in three patients, the maximal frequency of estimated TOPs was around 20 $\mathrm{cmH}_{2} \mathrm{O}$, and in the other two patients, this maximal frequency occurred at $30-35 \mathrm{cmH}_{2} \mathrm{O} .^{5}$

Among 24 critically ill patients with COVID-19 pneumonia in our study, the average of inspiratory plateau pressure applied in lung recruitment maneuver was $52.4 \pm 4.4 \mathrm{cmH}_{2} \mathrm{O}$, very close to the maximum estimate of the airway reopening pressure $49 \mathrm{cmH}_{2} \mathrm{O}$ under the condition that small airways were occluded by fluids like peanut butter (Fig. 6). This suggests that the changes in properties of lower airway secretions might be a mechanism responsible for high airway opening pressures in a majority of severe patients with COVID-19. This speculation can be further supported by low static compliance (mean $\pm[\mathrm{SD}], 23.1 \pm 7.3 \mathrm{~mL} /$ $\mathrm{cmH}_{2} \mathrm{O}$, Table 3), high alveolar dead space fraction (45 \pm 9 percent of tidal volume, Table 3 ), and particularly the $\mathrm{CO}_{2}$ waveform, whose shape relates to the airflow and emptying characteristics of the lung during each breath (Fig. 2). ${ }^{17} \mathrm{~A}$ decreased slope of the initial expiratory phase or a greater elevation angle of the expiratory plateau in capnograms indicate the existence of airway obstruction in patients with COVID-19 (panel $\mathrm{d}-\mathrm{f}$ in Fig. 2), while in some other patients, $\mathrm{ETCO}_{2}$ level reduced likely due to an increase in ventilation of dead space (panel b and c in Fig. 2). Finally, it can be seen from Table 3 that despite a plateau pressure of 45-60 $\mathrm{cmH}_{2} \mathrm{O}$, oxygen saturation of blood in these patients did not improve. These study data and clinical findings justify the present computational model.

\section{Limitations}

Our study has several limitations. First, estimation of the shear rates in Eqs. (2)-(4) may deviate from the real values at airway opening. In vitro model experiments have shown that the shear rates at airway opening are dependent on the type and thickness of the lining fluid as well as airway radius; second, we are unable to measure in situ the surface tension and viscosity of lower airway secretions in patients with COVID-19 for the time being because of the lack of a suitable measuring instrument, even data from in vitro measurement of the viscosity of secretions have not been reported due to barely accessible secretions samples.

Third, in estimating the critical opening velocity in each generation, we assumed that lung was homogenous and all airways of each generation were in the critical opening state. Actually, lungs of COVID-19 patients should be highly heterogeneous, and therefore the opening time and velocity in each generation must be different. Suki et al. ${ }^{28}$ demonstrated that airway openings occur in a series of avalanches whose magnitudes follow power-law distributions. The triggering of the avalanche process depends on the magnitude and timing of pressure excursions applied at the airway entrance during mechanical ventilation. On one hand, it should be noted that the real human bronchial tree is anatomically asymmetrical, that is, the number of divisions from the trachea to end branches varies along the different branch pathways. Under these circumstances flow in any branch is proportional the number of end branches for that branch, as described in the Horsfield model. ${ }^{10,11}$ This asymmetry of flow distribution among bronchial tree would lead to the difference in the airway opening velocities, which may in turn give rise to the different airway opening pressures even between daughter branches of a given generation. On the other hand, the current model of the airway reopening is static. In fact, the reopening of the collapsed airway is a dynamic process. Studies ${ }^{4,6,12}$ found that airway opening times range from tens to hundreds of milliseconds depending on inflation pressure, and particularly on physical properties of airway surface liquid in the patients with COVID-19. If the time 
course of the airway opening is long in a given airway opening pressure, so that the airway remains closed for a significant portion of inhalation, the improvements in oxygenation will still be small. As a result, a dynamic model taking the asymmetry of airway structure and airway opening time into account awaits further research.

Finally, we only considered the loss of pressure along the suction catheter caused by a very small amount of secretions $(0.2 \mathrm{~mL})$. In fact, the pressure loss from the alveoli upward to the tip of FOB is relatively greater due to smaller radii of these airways and bigger total length of airways $(>5.5 \mathrm{~cm})$ in Eq. (5). Taken together, we actually underestimated to a large extent the pressure loss during endotracheal suctioning.

\section{CONCLUSIONS}

The results of current computational simulations provided a possible explanation for what we have observed in the clinical treatment of patients with COVID-19 pneumonia-patients died suddenly in their activities of daily life such as defecating, eating or holding their breath. It was very likely that an acute increase of intrathoracic pressure in these activities resulted in massive atelectasis. The maximal transpulmonary pressure is approximately $25-30 \mathrm{cmH}_{2} \mathrm{O}$ in a healthy adult during spontaneous respiration, ${ }^{22}$ which is considerably less than the predicted airway opening pressures, probably $30-49 \mathrm{cmH}_{2} \mathrm{O}$, in the presence of sticky lower airway secretions. As a result patients could not open their lungs and eventually died from suffocation like drowning.

So can we suction these sticky secretions out of the distal airways? The current simulation data showed clearly that if the viscosity of mucus or secretions rose to the order of magnitude of about 10 poise, similar to that of medicinal glycerin at room temperature, it was impossible to pump mucus or secretions out of the deep airways by a FOB at the routine negative pressure of $7-13 \mathrm{kPa}$. Active airway humidification is therefore suggested during airway management in critically ill patients with COVID-19. We also recommend using effective expectorant drugs to dissolve mucus plugs and reduce mucus or secretion viscosity. During the subsequent mechanical ventilation, the settings of personalized plateau pressure or PEEP should be based on the apparent viscosity of mucus or secretions suctioned. For those who have a relatively high-viscosity lower airway secretions, other treatment regimens such as lung recruitment or extracorporeal membrane oxygenation (ECMO) should be considered as early as possible. ${ }^{26}$

\section{ACKNOWLEDGMENTS}

This work was supported by the National Natural Science Foundation of China (81971807, 11532003 and 31670950) and Special Project of the National Natural Science Foundation of China (82041003). We would like to express our gratitude to the patients who participated in this research and to all health-care workers involved in the diagnosis and treatment of patients in Wuhan.

\section{CONFLICT OF INTEREST}

No benefits in any form have been or will be received from a commercial party related directly or indirectly to the subject of this manuscript.

\section{ETHICS APPROVAL}

The study was approved by the Ethics Committee of Jinyintan Hospital in Wuhan, China (KY-2020-56.01).

\section{REFERENCES}

${ }^{1}$ Albaiceta, G. M., et al. Inspiratory vs. expiratory pressurevolume curves to set end-expiratory pressure in acute lung injury. Intensive Care Med. 31(10):1370-1378, 2005.

${ }^{2}$ Chen, N., et al. Epidemiological and clinical characteristics of 99 cases of 2019 novel coronavirus pneumonia in Wuhan, China: a descriptive study. The Lancet 395 (10223):507-513, 2020

${ }^{3}$ Chen, Z., et al. Determination of rheology and surface tension of airway surface liquid: a review of clinical relevance and measurement techniques. Respir. Res. 20(1):274, 2019.

${ }^{4}$ Chen, Z. L., et al. An estimation of mechanical stress on alveolar walls during repetitive alveolar reopening and closure. J. Appl. Physiol. 119(3):190-201, 2015.

${ }^{5}$ Crotti, S., et al. Recruitment and derecruitment during acute respiratory failure. Am. J. Respir. Crit. Care Med. 164 (1):131-140, 2001.

${ }^{6}$ Gaver, D. P., R. W. Samsel, and J. Solway. Effects of surface tension and viscosity on airway reopening. J. Appl. Physiol. 69(1):74-85, 1990.

${ }^{7}$ Otis, D. R. J., et al. Role of pulmonary surfactant in airway closure: a computational study. J. Appl. Physiol. 75 (3):1323-1333, 1993.

${ }^{8}$ Grasselli, G., et al. Baseline characteristics and outcomes of 1591 patients infected with SARS-CoV-2 admitted to ICUs of the Lombardy Region, Italy. JAMA 323(16):1574-1581, 2020.

${ }^{9}$ Guan, W.-J., et al. Clinical Characteristics of Coronavirus Disease 2019 in China. N. Engl. J. Med. 382:1708-1720, 2020.

${ }^{10}$ Horsfield, K., et al. Models of the human bronchial tree. $J$. Appl. Physiol. 31(2):207-217, 1971.

${ }^{11}$ Horsfield, K., W. Kemp, and S. Phillips. An asymmetrical model of the airways of the dog lung. J. Appl. Physiol. 52 (1):21-26, 1982. 
${ }^{12} \mathrm{Hsu}, \mathrm{S}$. H., et al. Role of viscoelasticity in the tube model of airway reopening. II. Non-Newtonian gels and airway simulation. J. Appl. Physiol. 80(5):1649-1659, 1996.

${ }^{13}$ Huang, C., et al. Clinical features of patients infected with 2019 novel coronavirus in Wuhan, China. The Lancet 395 (10223):497-506, 2020.

${ }^{14}$ Hughes, J. M., D. Y. Rosenzweig, and P. B. Kivitz. Site of airway closure in excised dog lungs: histologic demonstration. J. Appl. Physiol. 29(3):340-344, 1970.

${ }^{15}$ John, V. F., and D. F. Burton. Airway mucus function and dysfunction. N. Engl. J. Med. 363(23):2233-2247, 2010.

${ }^{16}$ Kacmarek, R. M., et al. Open lung approach for the acute respiratory distress syndrome: a pilot, randomized controlled trial. Crit. Care Med. 44(1):32-42, 2016.

${ }^{17}$ Krauss, B., et al. Capnogram shape in obstructive lung disease. Anesth. Analg. 100(3):884-888, 2005.

${ }^{18}$ Lai, S. K., et al. Micro- and macrorheology of mucus. $A d v$. Drug Deliv. Rev. 61(2):86-100, 2009.

${ }^{19}$ Lindgren, S., et al. Effectiveness and side effects of closed and open suctioning: an experimental evaluation. Intensive Care Med. 30(8):1630-1637, 2004.

${ }^{20} \mathrm{Liu}, \mathrm{Q}$, et al. Gross examination report of a COVID-19 death autopsy. J. Forensic Med. 36(1):21-23, 2020.

${ }^{21}$ Low, H. T., Y. T. Chew, and C. W. Zhou. Pulmonary airway reopening: effects of non-newtonian fluid viscosity. J. Biomech. Eng. 119(3):298-308, 1997.

${ }^{22}$ Lumb, A. PF Chapter 3 Elastic forces and lung volumes. In: Nunn's Applied Respiratory Physiology, 7th Edn, 2010. Televise Health Sciences. Edinburgh: Churchill Livingstone Elsevier.
${ }^{23}$ Macklem, P. T., D. F. Proctor, and J. C. Hogg. The stability of peripheral airways. Respir. Physiol. 8(2):191-203, 1970.

${ }^{24} \mathrm{McEwan}, \mathrm{A}$. D., and G. I. Taylor. The peeling of a flexible strip attached by a viscous adhesive. J. Fluid Mech. 26(1):1$15,2006$.

${ }^{25}$ Organization, W.H., Coronavirus disease (COVID-19) outbreak situation. 2020.

${ }^{26}$ Poston, J.T., B.K. Patel, and A.M. Davis, Management of critically ill adults with COVID-19. JAMA, 2020.

${ }^{27}$ Siobal, M. S. Monitoring exhaled carbon dioxide. Respir. Care 61(10):1397, 2016.

${ }^{28}$ Suki, B., et al. Avalanches and power-law behaviour in lung inflation. Nature 368(6472):615-618, 1994.

${ }^{29}$ Tian, S., et al., Pathological study of the 2019 novel coronavirus disease (COVID-19) through postmortem core biopsies. Modern Pathol., 2020.

${ }^{30} \mathrm{Wu}, \mathrm{C}$., et al. Risk factors associated with acute respiratory distress syndrome and death in patients with coronavirus disease 2019 pneumonia in Wuhan. China: JAMA Internal Medicine, 2020.

${ }^{31} \mathrm{Xu}, \mathrm{Z}$, et al., Pathological findings of COVID-19 associated with acute respiratory distress syndrome. The Lancet Respir. Med., 2020.

${ }^{32}$ Yang, X., et al., Clinical course and outcomes of critically ill patients with SARS-CoV-2 pneumonia in Wuhan, China: a single-centered, retrospective, observational study. The Lancet Respir. Med., 2020.

${ }^{33}$ Yap, D. Y., et al. Influences of parenchymal tethering on the reopening of closed pulmonary airways. J. Appl. Physiol. 76(5):2095-2105, 1994. 